\title{
Ovarian cystadenofibromas: a three cases report
}

\section{Hafsa Taheri*, Mohamed Reda Kholti, Asma Hmila, Hanane Saadi, Ahmed Mimouni}

Department of Obstetrics and Gynecology, University Hospital Mohammed VI, Oujda, Morocco

Received: 03 February 2020

Accepted: 29 February 2020

*Correspondence:

Dr. Hafsa Taheri,

E-mail: drtaheri.hafsa@gmail.com

Copyright: (C) the author(s), publisher and licensee Medip Academy. This is an open-access article distributed under the terms of the Creative Commons Attribution Non-Commercial License, which permits unrestricted non-commercial use, distribution, and reproduction in any medium, provided the original work is properly cited.

\begin{abstract}
Ovarian cystadenofibromas is a benign ovarian tumor that typically affects women in their fifth decade. Its risk factors remain unknown. This case study report 3 cases of ovarian cystadenofibromas treated in our department. The patients are aged 21, 28 and 50 years-old. The clinical pictures were polymorphic but the pelvic ultrasound of the case patients showed cystic ovarian masses suspected of malignancy. Two patients underwent laparoscopic ovarian cystectomy, and the third one, aged 50, underwent laparoscopic adnexectomy. The anatomopathological study showed benign ovarian cystadenofibromas. The operating follow ups were simple. It represents a relatively rare tumor whose macroscopic aspect evokes ovarian cancer wrongly leading to an aggressive surgical attitude.
\end{abstract}

Keywords: Cystadenofibroma, Laparoscopy, Ovary, Treatment

\section{INTRODUCTION}

Cystadenofibroma of the ovary is a rare benign tumor, which begins in the ovarian epithelium; it arises from germ lines and from the ovarian stroma. ${ }^{1}$ This tumor can be solid, cystic or semi-solid, depending on the fraction of epithelium and stroma it contains and the secretory activity of the epithelium that composes it. ${ }^{2}$ It can be taken for a malignant tumor of the ovary, hence the importance of the per-operative exploration and eventually the extemporaneous examination.

Study present three cases of ovarian cystadenofibromas treated in the study department.

\section{CASE REPORT}

\section{Clinical case 1}

The patient is 21-years-old women, nulliparous, with a medical history of spontaneous early miscarriage. During a pelvic ultrasound as part of the control of her miscarriage, a well limited cyst of the right ovary measuring 34/23 mm with an echogenic content, a bud of $6 \mathrm{~mm}$ and a thin wall was discovered (Figure 1, 2).

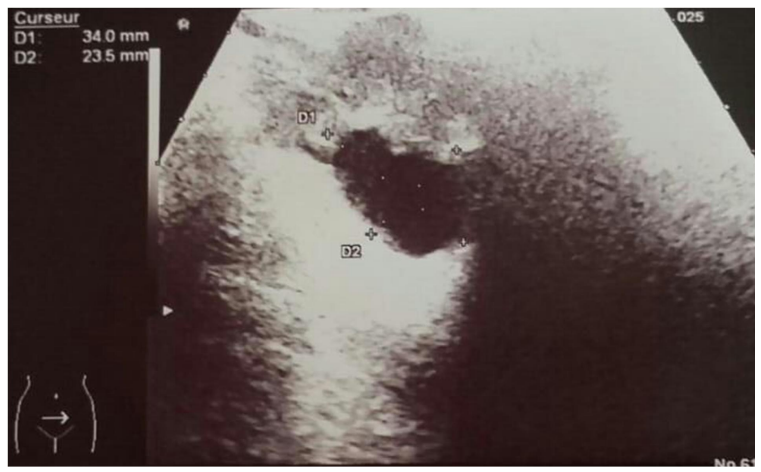

Figure 1: Ultrasound in which a well limited cyst of the right ovary measuring $34 / 23.5 \mathrm{~mm}$.

The patient underwent laparoscopy. We found a right para ovarian cyst with a thin whitish wall and no exokystic vegetation. The two ovaries seemed normal, neither effusion nor peritoneal carcinosis were noticed 
(Figure 3). A cystectomy was performed, with rupture of the cyst inside the endobag and release of a yellowish viscous liquid.

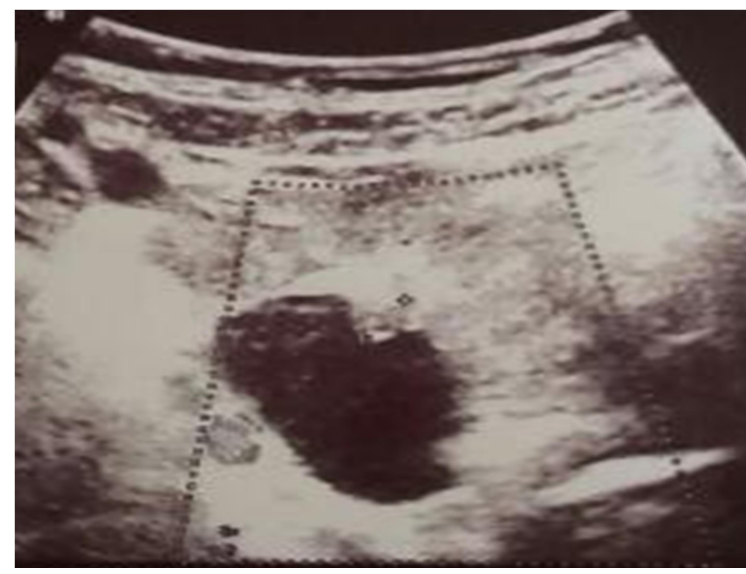

Figure 2: Well limited cyst of the right ovary with a finely heterogeneous anechoic content, a bud of $6 \mathrm{~mm}$ and a thin wall.

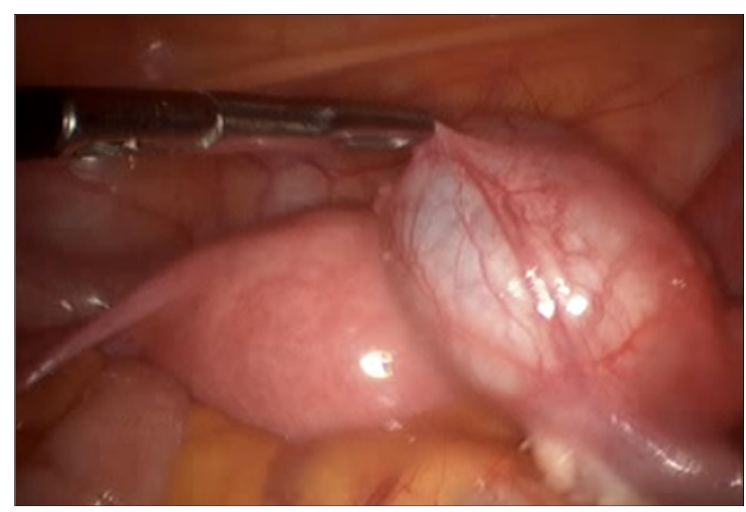

Figure 3: Laparoscopic aspect of the para ovarian cyst.

The result of the anatomopathological study showed a serous ovarian cystadenofibroma without histological sign of malignancy. After the surgery, the patient did not receive additional treatment beyond the regular checks.

\section{Clinical case 2}

This patient is 50 years-old. She is multiparous and menopaused. She consulted for a pelvic painless mass evolving for a year. The clinical examination found an overweight patient, with a pelvic mass of $80 \mathrm{~mm}$, of renitent consistency; the rest of the somatic examination was normal.

Pelvic ultrasonography showed a $135 \mathrm{~mm}$ finely echogenic thin-walled latero uterine image in favor of an ovarian cyst, with no peritoneal effusion. An abdominopelvic CT scan showed the presence of a hypodense image on the left ovary, with no evidence of peritoneal carcinosis (Figure 4). CA-125 was negative.

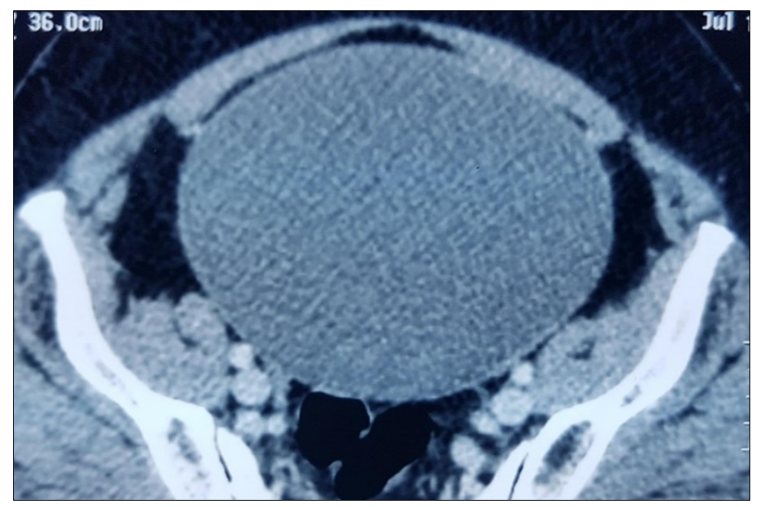

Figure 4: CT scan aspect of the ovarian cyst.

The patient underwent laparoscopy. A left ovarian cystic mass with smooth wall and without exocystic vegetation, neither ascites nor carcinosis signs were found. A left adnexectomy was performed; the anatomopathological results were in favor of a serous ovarian cystadenofibroma with peritoneal cytology free from malignant cells.

The post-operative follow ups were simple; the patient did not receive additional treatment beyond regular checks.

\section{Clinical case 3}

The patient is a 28 years-old multiparous patient, with no significant pathological history, who was suffering from chronic pelvic pain. Her clinic examination didn't show any abnormality. Her ultrasound exam showed a 72/52 $\mathrm{mm}$ multi-locular left ovarian cyst with endocystic vegetation taking arterial Doppler (Figure 5, 6). CA-125 was negative.

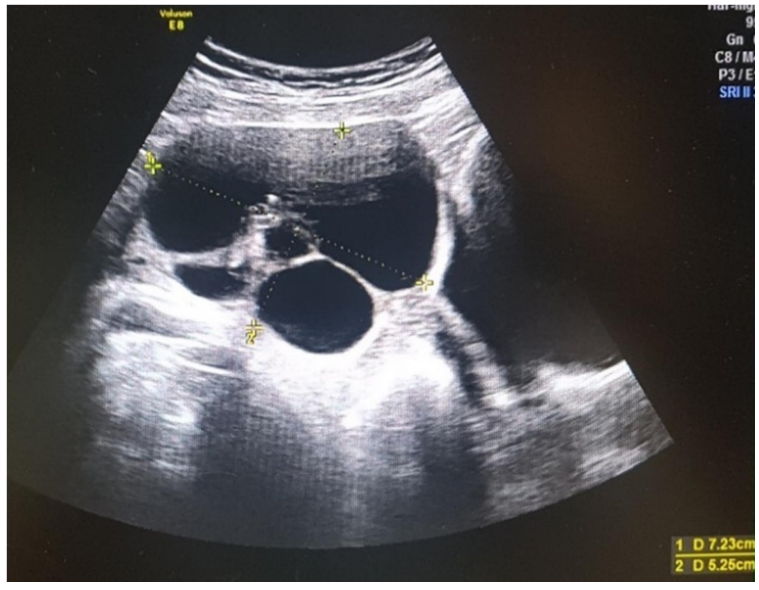

Figure 5: Ultrasound aspect of a mutilocular ovarian cyst of $72 \mathrm{~mm}$. 


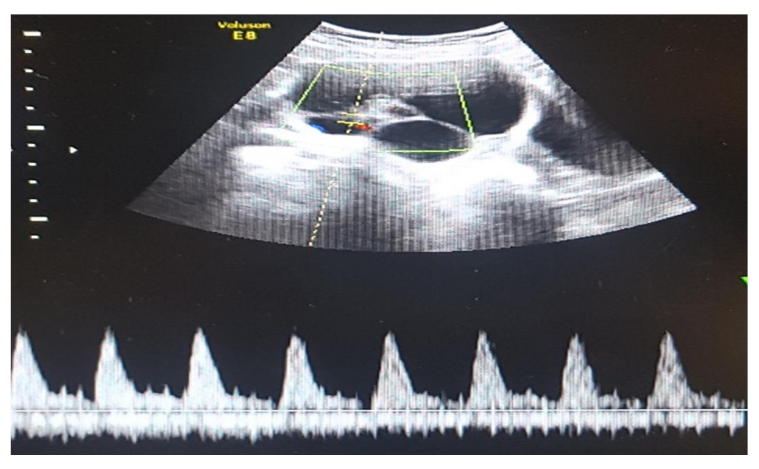

Figure 6: Ultrasound aspect of a multilocular ovarian cyst of $72 \mathrm{~mm}$ with arterial septal vascularization in Doppler imaging

The patient underwent a laparoscopy, no sign of carcinosis or malignancy were notices, so a left ovarian cystectomy and a peritoneal cytology were performed, the anatomopathological study found a serous ovarian cystadenofibroma.

The operating follow ups were simple and painless and no additional treatment undertaken.

\section{DISCUSSION}

Ovarian cystadenofibroma is relatively rare. Its actual incidence is unknown. These tumors frequently appear in women aged 40 to 50 , but they can affect younger women, especially when they have been exposed to disthylbene in utero. ${ }^{3}$ Cho et al estimate that these tumors account for approximately $1.7 \%$ of all benign ovarian tumors. 4

Risk factors for ovarian cystadenofibroma are unknown. However, overweight women and menopaused ones taking hormone replacement therapy are at increased risk. ${ }^{5}$

These tumors are classified, according to the types of their epithelial cells, as serous, endometrioid, mucinous or clear cells. ${ }^{6}$ The degree of epithelial proliferation and its relation to the stromal component of the tumor are the criteria used for classification as benign, borderline, or malignant, although almost the majority of the ovarian cystadenofibromas reported were benign.,

These tumors are most often asymptomatic. When they are bulky, they are likely to cause abdomino-pelvic pain, an increase in the abdominal perimeter or signs of organ's compression such as constipation or dysuria. ${ }^{7}$ Sometimes, they are revealed by menorrhagia or feminization signs that are secondary to tumor-induced hyperestrogenism. ${ }^{9}$

In most cases, the tumor is a single unilateral mass, but sometimes it can be either multiple masses at the expense of the same ovary or bilateral masses.
Radiologically, on endovaginal pelvic ultrasound, serous cystadenofibromas may look like a solitary cyst or a multilocular cystic mass, with septa or endocystic vegetations. In $50 \%$ of cases these images are vascularized on the Doppler. ${ }^{10}$

Pelvic ultrasound shows this tumor suspected of malignancy, and this is the case for the case two patients. Computed tomography (CT) is of limited value for the evaluation of this tumor. In a study by Cho et al, all 16 cases of ovarian cystadenofibromas, presenting complex cystic masses with solid components, were misdiagnosed as malignant ovarian tumors on $\mathrm{CT}$ scan or MRI. ${ }^{4}$ MRI has been described as the modality of choice for the characterization of complex ovarian masses. Outwater et al, described the characteristics of ovarian cystadenofibroma in MRI: a weak signal of the solid fibrous component of this tumor on T2 sequences. ${ }^{11}$ This finding has been described in more detail in several other reports. ${ }^{11,12}$

For the first observation, we had no reason to think about ovarian cancer before the intervention, since the pelvic imaging data and the anamnesis were soothing. Intraoperative laparoscopic findings have supported this hypothesis and the surgical strategy has focused on the most conservative management: ovarian cystectomy.

Ovarian cystadenofibromas can present several macroscopic characteristics usually belonging to ovarian cancer (vegetations, thick septa and walls, suspect intracystic fluid, abnormal vascularization of the ovarian cortex). It is therefore important for surgeons not to ignore the falsely disturbing morphological aspect of these ultimately benign tumors.

In such a context, it is therefore necessary to recall the interest of an extemporaneous examination in the management of an ovarian tumors suspected of malignancy, in order to conduct appropriate surgical management.

\section{CONCLUSION}

Given the rarity of ovarian cystadenofibroma, and its great similarity to ovarian cancer, a pelvic MRI seems very important in the diagnosis as well as the extemporaneous study, in order to avoid unnecessary invasive surgery.

Funding: No funding sources Conflict of interest: None declared Ethical approval: Not required

\section{REFERENCES}

1. Groutz A, Wolman I, Wolf Y, Luxman D, Sagi J, Jaffa AJ, et al. Cystadenofibroma of the ovary in young women. Eur J Obstet Gynecol. 1994;54(2):137-9. 
2. Wolfe SA, Seckinger DL. Varied anatomical types of ovarian adenofibroma. A proposed classification. Am J Obstet Gynecol. 1967;99:121-5.

3. Schmidt G, Fowler WC. Ovarian cystadenofibromas in three women with antenatal exposure to diethylstilbestrol. Gynecol Oncol. 1982;14:175-84.

4. Cho SM, Byun JY, Rha SE, Jung SE, Park GS, Kim $\mathrm{BK}$, et al. CT and MRI findings of cystadenofibromas of the ovary. Eur Radiol. 2004;14(5):798-804.

5. Lin HW, Tu YY, Lin SY, Su WJ, Lin WL, Lin WZ, et al. Risk of ovarian cancer in women with pelvic inflammatory disease: a population-based study. The Lancet Oncol. 2011;12(9):900-4.

6. Bell DA. Mucinous adenofibromas of the ovary. A report of 10 cases. Am J Surg Pathol. 1991;15:22732.

7. Czernobilsky B, Borenstein $\mathrm{R}$, Lancet $\mathrm{M}$. Cystadenofibroma of the ovary. A clinicopathologic study of 34 cases and comparison with serous cystadenoma. Cancer. 1974;34(6):1971-81.

8. Compton HL, Finck FM. Serous adenofibroma and cystadenofibroma of the ovary. Obstet Gynecol. 1970;36(4):636-45.
9. Bell DA, Scully RE. Atypical and borderline endometrioid adenofibromas of the ovary. A report of 27 cases. Am J Surg Pathol. 1985;9:205-14.

10. Alcázar JL, T Errasti, the judge Mínguez, Galán MJ, Garcia-Manero M, C Ceamanos sonographic features of ovarian cystadenofibromas: the spectrum. J Ultrasound Med Results. 2001;20:915-9.

11. Outwater EK, Siegelman ES, Talerman A, Dunton C. Ovarian fibromas and cystadenofibromas: MRI features of the fibrous component. J Magnet Reson Imag. 1997;7(3):465-71.

12. Takeuchi M, Matsuzaki K, Kusaka M, Shimazu H, Yoshida S, Nishitani $\mathrm{H}$, et al. Ovarian Cystadenofibromas: characteristics magnetic resonance findings and pathologic correlation $\mathrm{J}$ Comput Assist Tomogr. 2003;27:871-3.

Cite this article as: Taheri $\mathrm{H}$, Kholti MR, Hmila A, Saadi H, Mimouni A. Ovarian cystadenofibromas: a three cases report. Int J Reprod Contracept Obstet Gynecol 2020;9:1728-31. 